\title{
Role of systemic chemotherapy in the management of resected or resectable colorectal liver metastases: A systematic review and meta-analysis of randomized controlled trials
}

\author{
DOMENICO CILIBERTO ${ }^{1}$, UBALDO PRATI ${ }^{2}$, LAURA ROVEDA $^{2}$, VITO BARBIERI $^{1}$, \\ NICOLETTA STAROPOLI ${ }^{1}$, ALBERTO ABBRUZZESE $^{3}$, MICHELE CARAGLIA $^{3}$, MASSIMO DI MAIO $^{4}$, \\ DOMENICO FLOTTA $^{5}$, PIERFRANCESCO TASSONE ${ }^{1}$ and PIEROSANDRO TAGLIAFERRI ${ }^{1}$
}

\begin{abstract}
${ }^{1}$ Medical Oncology Unit and Center for Innovative Treatments, ${ }^{2}$ Surgical Oncology Unit, Magna Graecia University and Tommaso Campanella Cancer Center, Campus 'Salvatore Venuta', Catanzaro; ${ }^{3}$ Department of Biochemistry and Biophysics, Second University of Naples; ${ }^{4}$ Clinical Trials Unit, National Cancer Institute, Naples;

${ }^{5}$ Chair of Hygiene, Medical School, University of Catanzaro 'Magna Graecia', Catanzaro, Italy
\end{abstract}

Received December 1, 2011; Accepted February 23, 2012

DOI: $10.3892 /$ or.2012.1740

\begin{abstract}
Liver metastases are a common event in patients with colorectal cancer. Surgical resection, if feasible, produces a survival benefit. We performed a systematic review of randomized clinical trials (RCT) and meta-analysis to address the question if current available studies support the use of systemic chemotherapy as an adjunct to surgery in resected/ resectable patients. The search was based on major databases (PubMed, CancerLit, Embase, Medscape and Cochrane) of published literature and selecting abstracts from major cancer meetings. We performed a literature for the January 1982-May 2010 time frame. The hazard ratios (HRs), with confidence intervals, as presented in retrieved studies, referred to the disease- and/or progression-free (DFS and/or PFS) and overall survival (OS) were extracted. The meta-analysis was carried out by the fixed-effect and the random-effects model. Three studies randomizing combined treatment vs. surgery alone for a total of 666 patients (642 evaluable for survival analysis) were selected and included in the final analysis. Evidence for chemotherapy-induced benefit in terms of both DFS (pooled HR, 0.71; CI, 0.582-0.878; $\mathrm{P}=0.001$ ) and PFS (pooled HR, 0.75; CI, 0.620-0.910; $\mathrm{P}=0.003$ ) was demonstrated. However, our meta-analysis failed to demonstrate a significant advantage of combined treatment in terms of OS (pooled HR, 0.743; CI, 0.527-1.045; $\mathrm{P}=0.088$ ). Chemotherapy combined with surgical resection of colorectal liver metastases improves DFS and PFS whereas the benefit in OS is not demonstrated on
\end{abstract}

Correspondence to: Dr Pierosandro Tagliaferri, Medical Oncology Unit, Magna Graecia University and Tommaso Campanella Cancer Center, Campus 'Salvatore Venuta', Germaneto Catanzaro I-88100, Italy

E-mail: tagliaferri@unicz.it

Key words: systematic review, meta-analysis, colorectal cancer, resectable, resected, liver metastases, systemic chemotherapy the basis of the available results of RCTs. New prospective trials in the era of targeted therapy are eagerly awaited on this specific topic.

\section{Introduction}

Colorectal cancer (CRC) is a relevant cause of death in industrialized countries. At present, large bowel tumors are the second cause of male cancer mortality and the third cause of female cancer mortality (1-3).

The treatment of CRC is based on a multidisciplinary approach which includes surgery, radiotherapy and chemotherapy (4-9). Several clinical-pathological factors impact on the prognosis of patients suffering from CRC, but, among them, the stage of the disease at the diagnosis is the variable that mostly influences the final outcome (10). Based on these findings the selections of an appropriate therapeutic approach for hepatic metastases, which affect about half of CRC patients appears imperative $(11,12)$. To date, the surgical resection of hepatic metastases is the only treatment able to ensure longterm disease control (13). One possible explanation of the relevant efficacy of resection approaches is that the hepatic involvement occurs in a relatively early phase of the disease, when tumor cells do not express the end-stage aggressive phenotype (14). At present, it is not clear if all patients with hepatic lesions should undergo surgical evaluation (15). Up to some years ago, patients were selected on the basis of exclusion criteria referring to a higher risk of postsurgical relapse (16-18). Radical surgery now appears to be the most important condition for a long term survival (19-22). New surgical approaches like portal vein embolization, two-stage hepatectomy or their combination with local techniques (radiofrequency ablation, cryotherapy or laser therapy) can allow the resection of liver metastases that were considered not resectable in the past. Moreover, it has to be considered that chemotherapy can reduce the volume and the number of lesions, down-stage the disease and allow radical surgery (23). Guidelines have been developed with novel criteria of resectability based 
Table I. Quality assessment of the included studies.

\begin{tabular}{|c|c|c|c|c|c|c|}
\hline $\begin{array}{l}\text { Included } \\
\text { studies }\end{array}$ & $\begin{array}{c}\text { Method } \\
\text { of randomization }\end{array}$ & $\begin{array}{l}\text { Allocation } \\
\text { concealment }\end{array}$ & Blind & $\begin{array}{l}\text { Withdrawal } \\
\text { and dropout }\end{array}$ & Baseline & $\begin{array}{l}\text { Quality } \\
\text { level }\end{array}$ \\
\hline Langer et al (52) & Not detailed & Not detailed & No & Not mentioned & $\begin{array}{l}\text { Published in abstract form } \\
\text { and based on criteria of } \\
\text { enrollement including lung } \\
\text { metastases }\end{array}$ & $\mathrm{C}$ \\
\hline Portier et al (54) & Central by data center & Not detailed & No & Detailed criteria & Identical to baseline & B \\
\hline Nordlinger et al (55) & Central by data center & Central by data center & No & Detailed criteria & $\begin{array}{l}\text { Different timing and } \\
\text { schedule of chemotherapy }\end{array}$ & A \\
\hline
\end{tabular}

Quality criteria was adapted from the Cochrane reviewers' handbook.

on new technologies and knowledge on the biopathology of CRC (24). The 'OncoSurge' project was developed in order to set up a therapeutic algorithm which takes into account the patient's and the disease's features (25). These criteria are not influenced only by the radiological appearance of metastatic lesions since assessment of resectability must always take into account the functionality of the residual liver. Only $10-15 \%$ of hepatic lesions can be surgically resected at diagnosis; (26) this approach can produce survival up to 5 years of the $35 \%$ of the patients who, otherwise, would have no hope of longterm survival. Unfortunately, the failure rates are high with more than $75 \%$ of the patients experiencing relapse. In order to improve the outcome of patients undergoing resection of liver metastases, combination of chemotherapy with surgery along with rational selection of patients who potentially can obtain benefits from surgical resection has been proposed. Fluorouracil-based chemotherapy, as a primary treatment of CRC, is the mainstay approach to advanced disease with potential benefits in terms of quality of life and long-term survival (27). Benefits have been recently produced by new chemotherapeutic agents (irinotecan, oxaliplatin and oral fluoropyrimidines) and monoclonal antibodies (cetuximab, bevacizumab and panitumumab), which have gradually increased the average survival to about two years vs. six months of the pre-chemotherapy era (28).

It is clear that chemotherapy reduces the risk of relapse and also improves the resectability of primary and/or metastatic lesions (28-33). Upfront systemic chemotherapy has a role in the treatment of hepatic lesions combined to surgery: retrospective or small phase II prospective studies have shown that pre-operative chemotherapy can allow optimal surgery in unresectable disease (conversion chemotherapy). After neoadjuvant chemotherapy, surgical resection would be allowed in up to $30-50 \%$ of patients (34-37).

At present, the role of systemic chemotherapy adjunct to surgery in the treatment of resected or resectable hepatic metastases remains still undefined, as compared to conversion (neoadjuvant) chemotherapy whose role is more clearly established and is common practice in specialized institutions.

The aim of this study is to review and to meta-analyze the current evidence derived from prospective randomized trials for a clinical benefit of combinatory approaches based on chemotherapy plus surgery in the management of resected or resectable liver metastases in CRC as compared to surgery alone.

\section{Patients and methods}

Literature search. We retrieved the most widely recognized bibliographic sources (PubMed, CancerLit, Embase, Medscape and Cochrane) and selected the abstracts presented at the most important cancer meetings, between 1982, when treatment with 5-FU plus folinic acid was introduced becoming eventually the standard treatment, and May 2010. The published literature is rich in retrospective experiences of single or multi-institutions, but, in order to evaluate the role of systemic therapy, we considered the prospective studies only, in order to reduce or minimize the selection bias (31-37). The search was performed by the following key words: colorectal, tumor, cancer, liver, hepatic, metastases, lesions, chemotherapy, systemic, resectable, resected, prospective study, perioperative, adjuvant and neoadjuvant. The cited words and their combinations used were: colorectal cancer, liver metastases, hepatic lesions, resectable or resected metastases, systemic chemotherapy, perioperative or adjuvant and/or neoadjuvant chemotherapy. The 'related articles' function and the references retrieved from articles were used to perform the search of all related studies, abstracts and citations. For this search the selected language was English.

Selection. In the studies to be included in the present review, patients must have been enrolled according to: inclusion criteria. The studies should report: diagnosis of colorectal adenocarcinoma with resected/resectable liver metastases; age between 18 and 80; performance status according to ECOG scale between 0 and 2; good hepatic, renal function and normal full blood cell count or with toxicity $\leq 1$; no major comorbidities like cardiac or hepatic failure of moderate-serious degree, recent ischemic events, and other tumors (except for no melanoma skin cancers and local cervix tumor); no pregnancy or breast-feeding; informed consent and adhesion to bioethical standards according to the Declaration of Helsinki; adequate staging with at least an abdomen or pelvis CT or MR, thorax $\mathrm{X}$-Ray and electrocardiogram (ECG); and a minimum 24 months of follow-up. 


\section{QUOROM CHART}

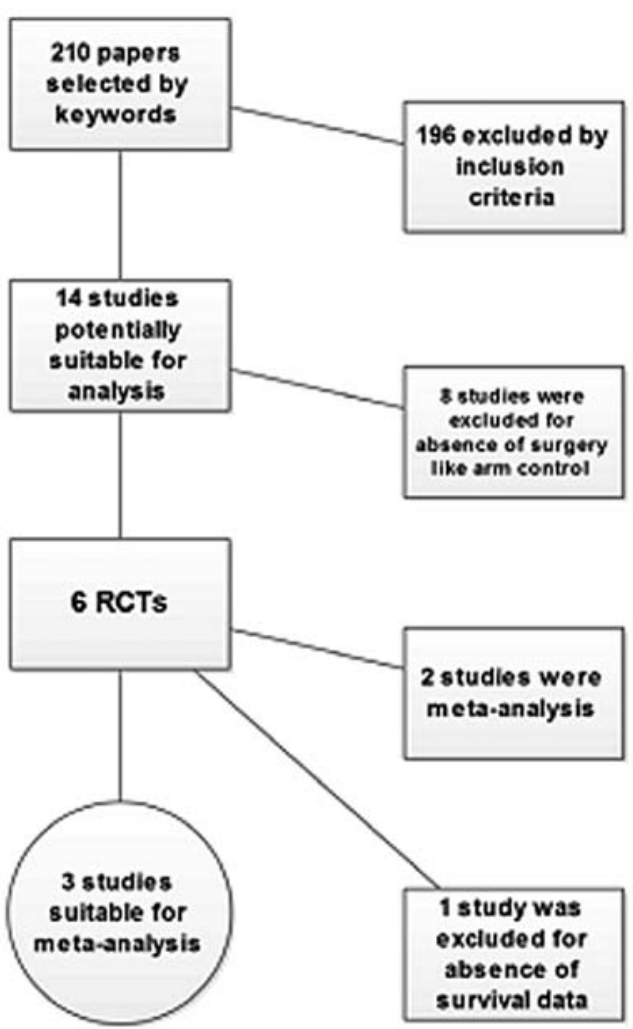

Figure 1. The Quality of Reporting of Meta-analyses (QUOROM) statement flow diagram.

Exclusion criteria. Non-comparative studies; non-prospective studies; other languages; non-comparable endpoints; different modality of administration of chemotherapy agents vs. systemic therapy (eg. intra-arterial infusion); studies including patients with unresectable liver disease were excluded.

Validity assessment. The quality assessment of selected studies was evaluated according to the Cochrane reviewers' handbook for four requirements: method of randomization, allocation concealment, blindness and adequacy of follow-up. One study was scored A (low risk of bias), one was scored B (intermediate risk of bias) and last study was scored $\mathrm{C}$ (high risk of bias) (Table I) (38).

Data extraction. The studies were examined independently by two investigators (D.C. and D.F.) in order to select homogeneous studies (39). First author, year of publication, study population characteristics, study design, inclusion and exclusion criteria, number of subjects, length of follow-up, short-term and long-term outcomes were extracted. Any discrepancies were resolved by an arbiter (P.T.). The major endpoint, evaluated in intention to treat analysis, was overall survival (OS). Other outcomes of interest were disease-free survival (DFS) for resected patients only and progressionfree survival (PFS) for resectable and resected patients, defined as secondary endpoints. The quality of selected RCTs was evaluated according to the Cochrane reviewers' handbook online version 5.0.2.
Quantitative data synthesis. A meta-analysis was carried out in order to evaluate the overall effects of the combined treatment (chemotherapy-surgery) on the predefined endpoints. Combined therapy was considered the experimental treatment while surgery alone represented the control. The results were extracted as hazard ratios (HRs) of DFS, PFS and OS. The interaction between survival endpoints and chemotherapy plus surgery was obtained through the single studies estimates from the HRs logarithm. The meta-analysis was carried out with the fixed-effects model, on the belief that the studies which have the same effect or meaning were homogeneous. The analysis was also carried out by the random-effect model taking in account the alternative hypothesis of heterogeneity based on the retrieval of three studies only for the final analysis. The combined analysis included the Cochrane's Q-test for the heterogeneity in the studies (40). Pooled data analysis was performed by the Cochran-Mantel-Haenszel test. Data were managed by STATA ${ }^{\mathrm{TM}}$ SE v. 10.0. (STATACorp., TX, USA) (41).

\section{Results}

Study characteristics. In the time frame covered by the systematic review (1982-2010), fourteen prospective studies were reported as full papers or congress abstracts. They dealt with the chemotherapy combined with surgery in the treatment of resected or resectable liver metastases (Fig. 1).

Eight studies were adjuvant or neoadjuvant phase II-III trials (42-49). These studies did not allow the evaluation of combinatory effects of surgery with chemotherapy, but they were useful to understand the toxicity and long-term effects. As shown in the Table II, neoadjuvant chemotherapy does not preclude the possibility to perform resections $\mathrm{R} 0$, even though surgery is delayed. It is clear that after two years of treatment a high percentage of patients (about 50\%) is free for relapse. Toxicities reported in studies were of low-moderate degree (42-49). Serious toxicities were typical of chemotherapy (diarrhea, emesis, thrombocytopenia and neutropenia); no toxic deaths were reported.

Two studies were not included in the analysis since they consisted of meta-analysis. The first, presented by Mitry et al (50) evaluated the role of the adjuvant chemotherapy after R0 resection, based on the results of two trials, showing no significant improvement of recurrence free-survival (RFS; $\mathrm{P}=0.058$ ), and a trend in terms of OS benefit for chemotherapy combined with surgery $(\mathrm{P}=0.125)$. The second meta-analysis examined the role of the systemic or hepatic arterial chemotherapy after surgery. Carrying out this kind of analysis, Uzzan et al (51) circumvented the low statistical power of the studies and showed that the locoregional plus systemic chemotherapy is able to determine a significant advantage, though small, on overall and relapse free survival, [HR OS, 0.81 (95\% CI, 0.670.99; $\mathrm{P}=0.04)$ and HR RFS, 0.77 (95\% CI, 0.67-0.89; $\mathrm{P}=0.001)]$.

We selected four trials that appeared suitable for a metaanalytic evaluation on the predefined endpoints. The first study by Langer et al (52) has only been presented as an abstract at the ASCO Meeting in 2002. The primary endpoint was the efficacy of chemotherapy with 5-fluorouracil (5-FU) plus folinic acid after resection of liver metastases, vs. surgery only. One hundred and twenty-nine patients were randomized, 
Table II. Phase II-III trials evaluated for systemic chemotherapy in resectable liver disease in CRC patients.

\begin{tabular}{|c|c|c|c|c|c|}
\hline Studies (Ref) & Study design & Treatment & $\mathrm{n}$ & Resected (\%) & DFS rate $(\%)$ \\
\hline Lorenz et al (44) & Neoadjuvant & FOLFOX & 42 & 81 & ND \\
\hline $\begin{array}{l}\text { Wein et al (43) } \\
2010 \text { update (46) }\end{array}$ & Neoadjuvant & $\mathrm{OX}+\mathrm{HD} 5-\mathrm{FU}$ & 20 & 80 & $\begin{array}{l}52 \text { ( } 2 \text { years }) \\
25 \text { ( } 5 \text { years })\end{array}$ \\
\hline $\begin{array}{l}\text { Bathe } \text { et al (42) } \\
2009 \text { update (47) }\end{array}$ & Neoadjuvant & FOLFIRI & $\begin{array}{c}\text { ND } \\
35\end{array}$ & $\begin{array}{c}\text { ND } \\
85\end{array}$ & $\begin{array}{l}\text { ND } \\
\text { ND }\end{array}$ \\
\hline Taieb et al (45) & Perioperative & $\begin{array}{c}\text { FOLFOX-7 followed } \\
\text { by FOLFIRI }\end{array}$ & 47 & 100 & 47 (2 years) \\
\hline Lubezky et al (48) & $\begin{array}{l}\text { Adjuvant vs. } \\
\text { perioperative }\end{array}$ & FOLFOX or FOLFIRI & 105 & 53 & ND \\
\hline Ychou et al (49) & Adjuvant & FUFA vs. FOLFIRI & 306 & 100 & ND \\
\hline
\end{tabular}

DFS, disease-free survival; ND, no data; OX+HD, oxaliplatin + high dose; CRC, colorectal cancer.

Table III. Selected four trials suitable for a meta-analytic evaluation on the predefined endpoints.

\begin{tabular}{|c|c|c|c|c|c|c|}
\hline \multicolumn{7}{|l|}{ Langer et al (52) } \\
\hline & Treatment & Study arm & $\begin{array}{l}\text { Median DFS } \\
\text { (months) }\end{array}$ & $\begin{array}{c}\text { 4-year DFS } \\
\% \text { mean (range) }\end{array}$ & $\begin{array}{l}\text { Median OS } \\
\text { (months) }\end{array}$ & $\begin{array}{c}\text { 4-year OS } \\
\% \text { mean (range) }\end{array}$ \\
\hline & Adjuvant FUFA & $\begin{array}{c}\text { Arm } 1(\mathrm{n}=52) \\
(\mathrm{CHT}+\mathrm{S})\end{array}$ & 39 & $45(29-61)$ & 53 & $57(41-73)$ \\
\hline & & Arm $2(n=55)(S)$ & 20 & $35(21-50)$ & 43 & $47(31-63)$ \\
\hline & & & \multicolumn{2}{|c|}{$\underline{\mathrm{HR} \text { (S vs. CHT+S), CI 95\% }}$} & \multicolumn{2}{|c|}{ HR (S vs. CHT+S), CI 95\% } \\
\hline & & & & $\begin{array}{c}1.28(0.76-2.14) \\
P=0.35\end{array}$ & & $\begin{array}{c}1.30(0.71-2.36) \\
P=0.39\end{array}$ \\
\hline \multicolumn{7}{|l|}{ Portier et al (54) } \\
\hline & Treatment & Study arm & $\begin{array}{l}\text { Median DFS } \\
\text { (months) }\end{array}$ & 5-year DFS (\%) & $\begin{array}{l}\text { Median OS } \\
\text { (months) }\end{array}$ & 5 -year OS (\%) \\
\hline & Adjuvant FUFA & $\begin{array}{c}\text { Arm } 1(\mathrm{n}=86) \\
(\mathrm{CHT}+\mathrm{S})\end{array}$ & 24.4 & $33.5(\mathrm{SE}=5.4)$ & 62.1 & $51.1(\mathrm{SE}=5.7)$ \\
\hline & & $\operatorname{Arm} 2(n=85)(S)$ & 17.6 & $26.7(\mathrm{SE}=5.1)$ & 46.4 & $41.9(\mathrm{SE}=5.7)$ \\
\hline & & & \multicolumn{2}{|c|}{ 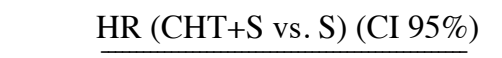 } & \multicolumn{2}{|c|}{ HR (CHT+S vs. S) (CI 95\%) } \\
\hline & & & & $0.66(0.46-0.96)$ & & $0.73(0.48-1.10)$ \\
\hline & & & & $\mathrm{P}=0.028$ & & $\mathrm{P}=0.13$ \\
\hline \multicolumn{7}{|l|}{ Nordlinger et al (55) } \\
\hline & Treatment & $\begin{array}{c}\text { Arm } 1 \\
\text { patients } \\
(\mathrm{CHT}+\mathrm{S}), \mathrm{n}\end{array}$ & $\begin{array}{c}\text { Arm } 2 \\
\text { patients }(\mathrm{S}), \mathrm{n}\end{array}$ & $\begin{array}{l}\text { \% Absolute } \\
\text { difference in } \\
\text { 3-year PFS }\end{array}$ & $\begin{array}{l}\text { Hazard ratio } \\
\text { (CI 95\%) }\end{array}$ & P-value \\
\hline & $\begin{array}{l}\text { Perioperative } \\
\text { FOLFOX-4 }\end{array}$ & & & & & \\
\hline All patients & & 182 & 182 & $+7.2(28.1-35.4)$ & $0.79(0.62-1.02)$ & 0.058 \\
\hline All eligible patients & & 171 & 171 & $+8.1(28.1-36.2)$ & $0.77(0.60-1.00)$ & 0.041 \\
\hline All resected patents & & 151 & 152 & $+9.2(33.2-42.4)$ & $0.73(0.55-0.97)$ & 0.025 \\
\hline
\end{tabular}

Lopez-Ladron et al (53)

ND

DFS, disease-free survival; OS, overall survival; HR, hazard ratio; SE, standard error; CHT, chemotherapy; S, surgery; PFS, progression-free survival; ND, no data. 


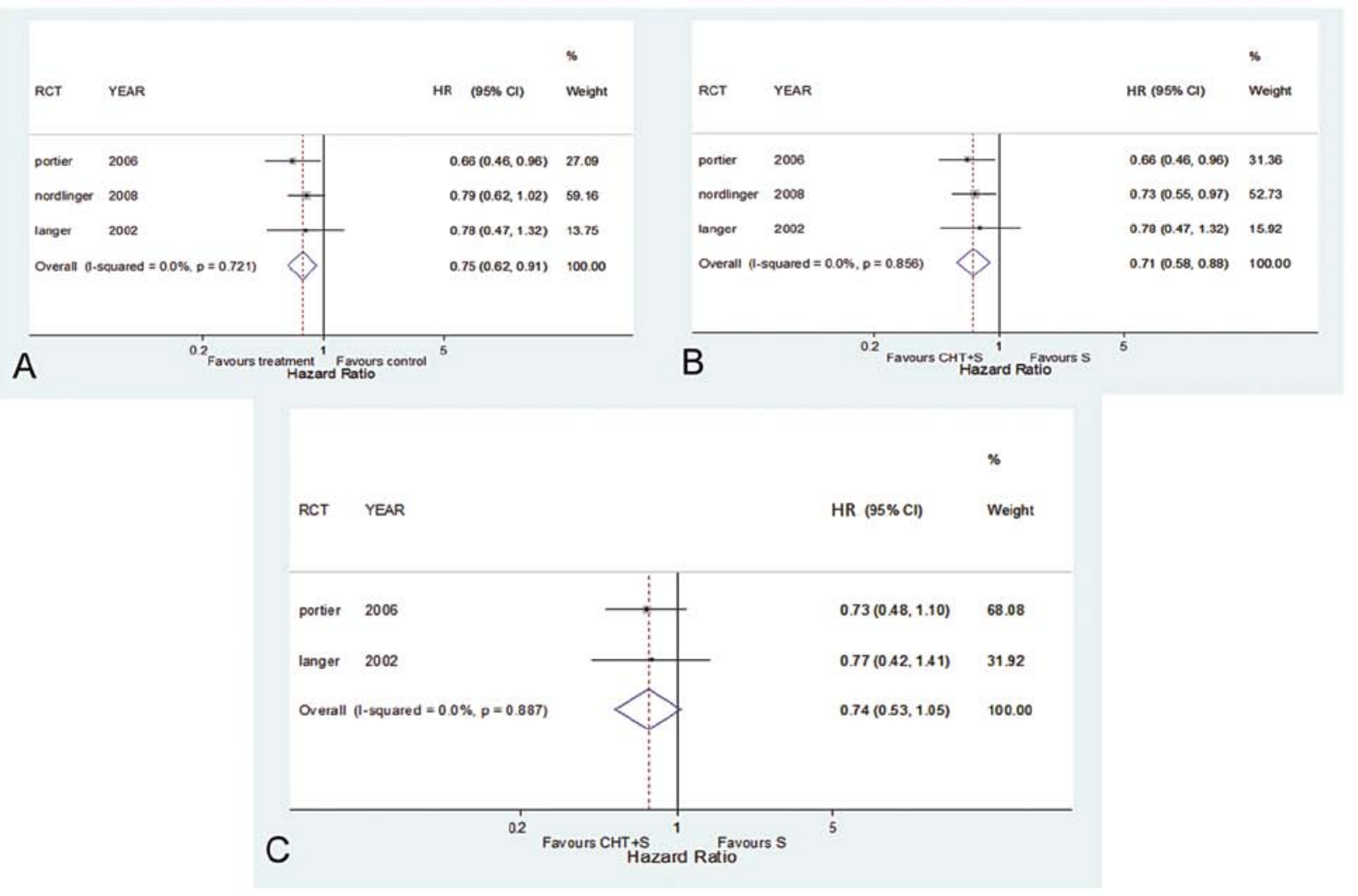

Figure 2. (A) Meta-analysis of HRs in terms of PFS in valuable patients (TEST HR, 1; Z, 2.93; $\mathrm{P}=0.003$ ). (B) Meta-analysis of HRs in terms of DFS in resected patients (TEST HR, $1 ; \mathrm{Z}, 3.19 ; \mathrm{P}=0.001$ ). (C) Meta-analysis of HRs in terms of OS in valuable patients (TEST HR, $1 ; \mathrm{Z}, 1.71 ; \mathrm{P}=0.088$ ).

among them 107 were evaluable for the survival analysis. The Lopez-Ladron et al (53) study, presented as an abstract at the ASCO meeting in 2003, was excluded from the analysis, since, though it had a design similar to other studies, there was no adequate follow-up (only 15 months) and the authors did not present any survival analysis, but they simply reported the average survival in the two groups (30 months in the chemotherapy-surgery group and 15 months in the surgery group). The second trial by Portier et al (54) selected for the analysis was a multicenter randomized study with the same design and treatment of the previous one, but with a greater number of patients. One hundred and seventy-three patients were randomized, 171 valuable for intention-to-treat analysis with an 87-month follow-up. In this study the patients were stratified for gender, age and lesion number. After adjustment for the most influential prognostic factors, the 5-years-DFS rate was $33.5 \%$ in the chemotherapy arm and $26.7 \%$ in the control. The 5-years-OS rate was $51.1 \%$ in the chemotherapy arm and $41.1 \%$ in the surgery group.

The last study selected for analysis was that of Nordlinger et al (55). Unlike previous studies, the aim of this trial was the comparison between a perioperative chemotherapy and surgery alone. The treatment schedule was FOLFOX-4, administered for six cycles before and after surgery. In the study 364 patients were randomized, fairly divided in the two treatment groups (182:182); one hundred and seventy-one patients were found to be eligible in each group. The study design was aimed to demonstrate a $10 \%$ increase of PFS vs. surgery only. The survival analysis was performed on an intention-to-treat population (Table III).
Quantitative data synthesis. We analyzed the hazard ratios (HRs), with HR confidence intervals (CIs), as presented in the studies, referred to the DFS and OS. We selected this analysis in order to compare the survival in different studies, since it takes into account the change of the risk in the patients during that time. The influence of single studies was evaluated by the HRs logarithm (CIs 95\%). Evidence in favor of chemotherapy plus surgery vs. surgery alone was derived from the HR analysis both in terms of PFS (pooled HR, 0.75; CI 95\%, 0.620-0.910; $\mathrm{P}=0.003$, Figs. $2 \mathrm{~A}$ and $3 \mathrm{~A}$ ) in the study where chemotherapy was performed in the perioperative setting and of DFS (pooled HR, 0.71; CI 95\%, 0.582-0.878; $\mathrm{P}=0.001$, Fig. $2 \mathrm{~B}$ and $3 \mathrm{~B}$ ) in studies where chemotherapy was performed in the post-surgical setting and which achieved successful resection on the basis of study design. We failed to demonstrate an overall survival benefit but only a trend advantage for the combined treatment compared to surgery alone (pooled HR, 0.743; CI 95\%, 0.527-1.045; P=0.088, Fig. 2C and 3C). We did not include in the last analysis the study of Nordlinger et al where survival data have not been presented due to inadequate follow-up at the time of analysis for publication.

\section{Discussion}

We performed a systematic review in order to conduct a metaanalysis of studies evaluating if perioperative (neoadjuvant and/or adjuvant) chemotherapy has an impact on the survival and general outcome of CRC patients with resectable liver disease. In our search we excluded other approaches including 


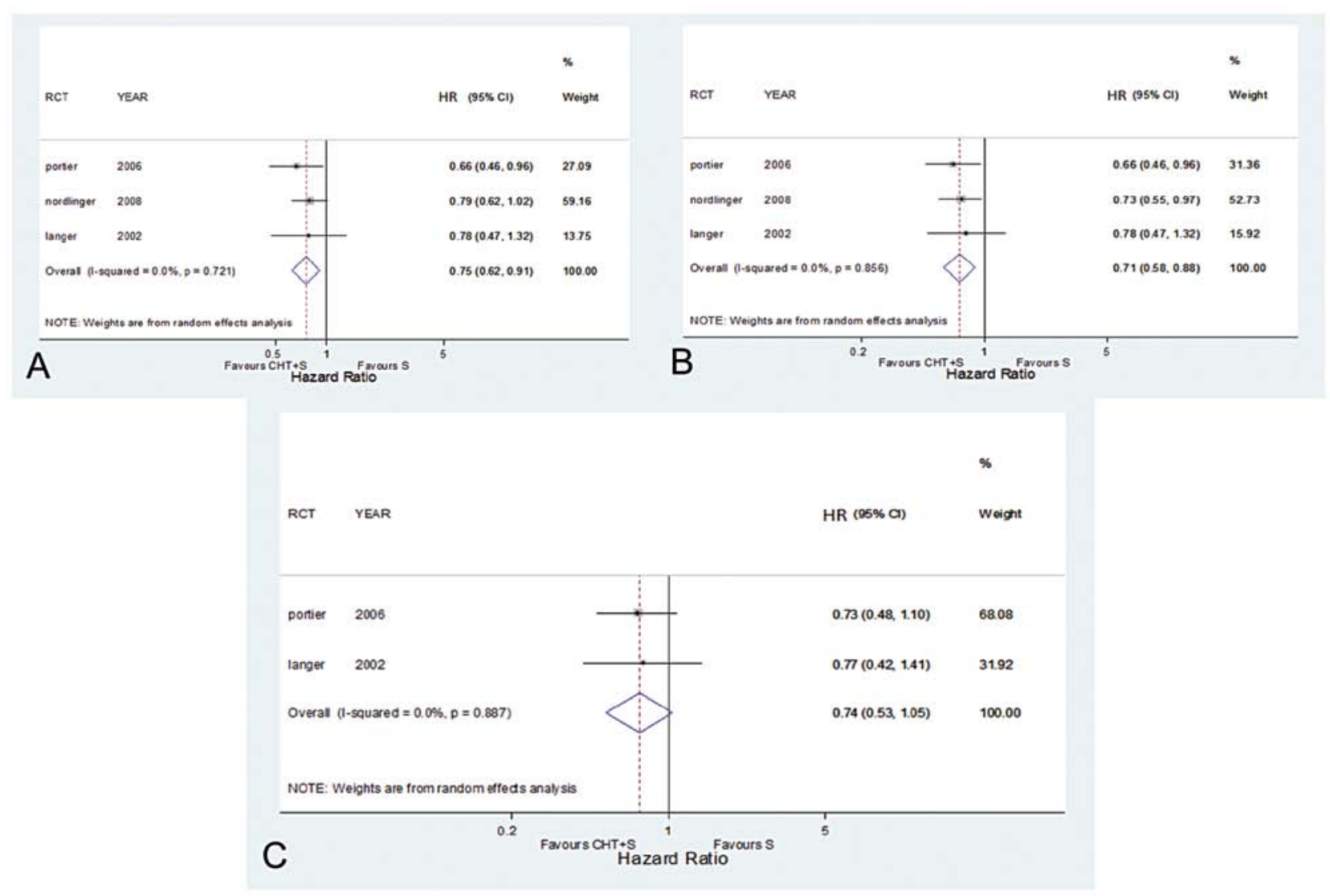

Figure 3. (A) Meta-analysis of HRs in terms of PFS in valuable patients (TEST HR, 1; Z, 2.93; P=0.003). (B) Meta-analysis of HRs in terms of DFS in resected patients (TEST HR, 1; $\mathrm{Z}, 3.19 ; \mathrm{P}=0.001$ ). (C) Meta-analysis of HRs in terms of OS in valuable patients (TEST HR, $1 ; \mathrm{Z}, 1.71 ; \mathrm{P}=0.088$ ). All analysis were performed with a random effect model.

intraarterial or other locoregional infusional techniques because their use is limited to highly experienced single institutions. We demonstrated that the combined treatment was effective in terms of DFS and PFS but not in terms of OS.

The lack of evidence in our meta-analysis of an OS benefit does not necessarily indicate a lack of effect of the combined treatment if we consider that in CRC, DFS and PFS are considered surrogate of OS benefit as demonstrated by different literature-based analyses (56-59). It can be hypothesized therefore that a long-term follow-up could have led to the formal evidence of such a benefit.

A limit of our meta-analysis is that it does not allow to solve the problem if the perioperative treatment should be given with a predefined number of courses or may be individualized based on the patient response. Prospective studies may be designed with this aim. An additional point, at present, is that the choice among the different drugs and schedules is not unambiguous, but it depends on different factors. In the case of a resectable disease an aggressive (i.e. FOLFOX-IRI) fourdrug combination in the preoperative chemotherapy could allow surgery with the possibility to spare hepatic parenchyma in order to preserve liver function (60). In 2005 Folprecht $e t$ al pointed out that the possibility to undergo an R0 surgery was directly correlated to the response to the neoadjuvant chemotherapy (61). Radical surgery is the main endpoint of neoadjuvant chemotherapy; even if the results obtained by a medical treatment are excellent in terms of short-term control of the disease, they will eventually fail in a long-term period
(62). This risk was underlined by a retrospective study by Benoist et al in 2006 (63), where the authors analyzed the outcome of patients that had had a complete clinical response to systemic chemotherapy. All patients underwent surgery of the liver areas where some lesions had been identified before chemotherapy (63). The results of this study pointed out that, even in the presence of a complete radiological response, one third of patients had a macroscopic residual disease at surgery and the $80 \%$ of resected areas, even in the absence of an evident illness, included neoplastic cells. Adjuvant therapy could also be used in order to fill the current gap of imaging techniques, which are unable to identify the residual microscopic disease and to identify 'cured' patients (64).

The growing interest for biological agents like cetuximab or bevacizumab in the perioperative setting indicate the need of prospectively designed studies. At present, proof-of-principle of benefit for these biological agents comes from retrospective studies in the neoadjuvant setting but no data are available on the perioperative setting in patients with resectable disease or in the post-resection setting (65).

In conclusion, the purpose of a meta-analysis is not to modify the clinical practice, but to raise questions in order to challenge the current beliefs and/or to design prospective studies. We think that our results provide support to the general view that patients with resectable liver lesions should be evaluated not only for surgery but also for systemic treatment, since such approach provides benefit in terms of PFS and DFS and is overally well-tolerated. This meta-analysis, however, does 
not demonstrate statistical significant benefit in OS of the peri-operative systemic treatment and this point needs to be addressed in prospective trials including last generation drugs and biologicals.

\section{References}

1. Jemal A, Siegel R, Xu J and Ward E: Cancer statistics, 2010. CA Cancer J Clin 60: 277-300, 2010.

2. Parkin DM, Bray F, Ferlay J and Pisani P: Global cancer statistics, 2002. CA Cancer J Clin 55: 74-108, 2005.

3. Benson AB III: Epidemiology, disease progression, and economic burden of colorectal cancer. J Manag Care Pharm 13 (6 Suppl C): S5-S18, 2007.

4. Meyerhardt JA and Mayer RJ: Systemic therapy for colorectal cancer. N Engl J Med 352: 476-487, 2005.

5. Gennari L, Russo A and Rossetti C: Colorectal cancer: what has changed in diagnosis and treatment over the last 50 years? Tumori 93: 235-241, 2007.

6. Kosmider S and Lipton L: Adjuvant therapies for colorectal cancer. World J Gastroenterol 13: 3799-3805, 2007.

7. Wolpin BM, Meyerhardt JA, Mamon HJ and Mayer RJ: Adjuvant treatment of colorectal cancer. CA Cancer J Clin 57: 168-185, 2007.

8. Sauer R, Becker H, Hohenberger W, et al: German Rectal Cancer Study Group: Preoperative versus postoperative chemoradiotherapy for rectal cancer. N Engl J Med 351: 1731-1740, 2004.

9. ESMO Guidelines Working Group, Van Cutsem EJ: Advanced colorectal cancer: ESMO clinical recommendations for diagnosis,treatment and follow-up. Ann Oncol 18 (Suppl 2): ii25-6, 2007.

10. O'Connell JB, Maggard MA and Ko CY: Colon cancer survival rates with the new American Joint Committee on Cancer sixth edition staging. J Natl Cancer Inst 96: 1420-1425, 2004.

11. Wagner JS, Adson MA, Van Heerden JA, Adson MH and Ilstrup DM: The natural history of hepatic metastases from colorectal cancer. A comparison with resective treatment. Ann Surg 199: 502-508, 1984.

12. McMillan DC and McArdle CS: Epidemiology of colorectal liver metastases. Surg Oncol 16: 3-5, 2007.

13. Al-Asfoor A and Fedorowicz Z: WITHDRAWN: Resection versus no intervention or other surgical interventions for colorectal cancer liver metastases. Cochrane Database Syst Rev 17: CDUO6039, 2007.

14. Stein U and Schlag PM: Clinical, biological, and molecular aspects of metastasis in colorectal cancer. Recent Results Cancer Res 176: 61-80, 2007.

15. McLoughlin JM, Jensen EH and Malafa M: Resection of colorectal liver metastases: current perspectives. Cancer Control 13: 32-41, 2006.

16. Adson MA: Resection of liver metastases: When is it worthwhile? World J Surg 11: 511-520, 1987.

17. Scheele J, Stangl R, Altendorf-Hofman A, et al: Resection of colorectal liver metastases. World J Surg 19: 59-71, 1995.

18. Resection of the liver for colorectal carcinoma metastases: A multi-institutional study of indications for resection-registry of hepatic metastases. Surgery 103: 278-288, 1988.

19. Stangl R, Altendorf-Hofman A, Charnley RM, et al: Factors influencing the natural history of colorectal liver metastases. Lancet 343: 1405-1410, 1994.

20. Jaeck D, Bachellier P, Guiguet M, et al: Long-term survival following resection of colorectal hepatic metastases. Association Francaise de Chirurgie. Br J Surg 84: 977-980, 1997.

21. Fong Y, Cohen AM, Fortner JG, et al: Liver resection for colorectal metastases. J Clin Oncol 15: 938-946, 1997.

22. Scheele J, Altendorf-Hofmann A, Grube T, et al: Resection of colorectal liver metastases: what prognostic factors determine patient selection? Chirurg 72: 547-560, 2001 (In German).

23. Pawlik TM, Schulick RD and Choti MA: Expanding criteria for resectability of colorectal liver metastases. Oncologist 13: 51-64, 2008.

24. Garden OJ, Rees M, Poston GJ, et al: Guidelines for resection of colorectal cancer liver metastases. Gut 55 (Suppl 3): iiil-iii8, 2006.

25. Poston GJ, Adam R, Alberts S, et al: OncoSurge: a strategy for improving resectability with curative intent in metastatic colorectal cancer. J Clin Oncol 23: 7125-7134, 2005.

26. Steele G Jr and Ravikumar TS: Resection of hepatic metastases from colorectal cancer. Biologic perspective. Ann Surg 210: $127-138,1989$.
27. Cunningham D, Atkin W, Lenz HJ, Lynch HT, Minsky B, Nordlinger B and Starling N: Colorectal cancer. Lancet 375: 1030-1047, 2010.

28. Gallagher DJ and Kemeny N: Metastatic colorectal cancer: from improved survival to potential cure. Oncology 78: 237-248, 2010.

29. Bozzetti F, Doci R, Bignami P, Morabito A and Gennari L: Patterns of failure following surgical resection of colorectal cancer liver metastases: rationale for a multimodal approach. Ann Surg 205: 264-270, 1987.

30. Topal B, Kaufman L, Aerts R and Penninckx F: Patterns of failure following curative resection of colorectal liver metastases. Eur J Surg Oncol 29: 248-253, 2003.

31. Delaunoit T, Alberts SR, Sargent DJ, et al: Chemotherapy permits resection of metastatic colorectal cancer: experience from Intergroup N9741. Ann Oncol 16: 425-429, 2005.

32. Bismuth H, Adam R, Levi F, et al: Resection of non-resectable liver metastases from colorectal cancer after neoadjuvant chemotherapy. Ann Surg 224: 509-520, 1996.

33. Adam R, Huguet E, Azoulay D, et al: Hepatic resection after down-staging of unresectable hepatic colorectal metastases. Surg Oncol Clin N Am 12: 211-220, 2003.

34. Giacchetti S, Itzhaki M, Gruia G, et al: Long-term survival of patients with unresectable colorectal cancer liver metastases following infusional chemotherapy with 5-fluorouracil, leucovorin, oxaliplatin and surgery. Ann Oncol 10: 663-669, 1999.

35. Adam R, Delvart V, Pascal G, et al: Rescue surgery for unresectable colorectal liver metastases downstaged by chemotherapy: A model to predict long-term survival. Ann Surg 240: 644-657, 2004.

36. Pozzo C, Basso M, Quirino M, et al: Long-term follow-up of colorectal cancer (CRC) patients treated with neoadjuvant chemotherapy with Irinotecan and fluorouracil plus folinic acid (5-FU/FA) for unresectable liver metastases. Br J Cancer 97: 1035-1039, 2007.

37. Alberts SR, Horvath WL, Sternfeld WC, et al: Oxaliplatin, fluorouracil, and leucovorin for patients with unresectable liveronly metastases from colorectal cancer: a North Central Cancer Treatment Group phase II study. J Clin Oncol 23: 9243-9249, 2005.

38. Higgins JPT and Green S (eds): Cochrane Handbook for Systematic Reviews of Interventions Version 5.0.2 (updated September 2009). The Cochrane Collaboration, 2009. Available from: www.mrc-bsu.cam.ac.uk/cochrane/handbook502.

39. Begg CB and Mazumdar M: Operating characteristics of a rank correlation test for publication bias. Biometrics 50: 1088-1101, 1994.

40. Deeks, JJ, Altman DG and Bradburn MJ: Statistical methods for examining heterogeneity and combining results from several studies in meta-analysis. In: Systematic Reviews in Health Care: Meta-Analysis in Context. Egger M, Smith GD and Altman DG (eds). 2nd edition. BMJ Publication Group, London, 2001.

41. Sterne JAC, Harris RJ, Harbord RM and Steichen TJ: Userwritten packages for meta-analysis in Stata, 2007. Available from: http://www.stata.com/support/fags/stat/meta.html/

42. Bathe OF, Dowden S, Sutherland F, et al: Phase II study of neoadjuvant 5-FU + leucovorin + CPT-11 in patients with resectable liver metastases from colorectal adenocarcinoma. BMC Cancer 4: $32,2004$.

43. Wein A, Riedel C, Brückl W, et al: Neoadjuvant treatment with weekly high-dose 5-Fluorouracil as 24-hour infusion, folinic acid and oxaliplatin in patients with primary resectable liver metastases of colorectal cancer. Oncology 64: 131-138, 2003.

44. Lorenz M, Staib-Sebler E, Gog C, et al: Prospective pilot study of neoadjuvant chemotherapy with 5- fluorouracil, folinic acid and oxaliplatin in resectable liver metastases of colorectal cancer. Analysis of 42 neoadjuvant chemotherapies. Zentralbl Chir 128: 87-94, 2003.

45. Taïeb J, Artru P, Paye F, et al: Intensive systemic chemotherapy combined with surgery for metastatic colorectal cancer: results of a phase II study. J Clin Oncol 23: 502-509, 2005.

46. Boxberger F, Albrecht H, Konturek PC, et al: Neoadjuvant treatment with weekly high-dose 5-fluorouracil as a $24 \mathrm{~h}$-infusion, folinic acid and biweekly oxaliplatin in patients with primary resectable liver metastases of colorectal cancer: long-term results of a phase II trial. Med Sci Monit 16: CR49-CR55, 2010.

47. Bathe OF, Ernst S, Sutherland FR, et al: A phase II experience with neoadjuvant irinotecan (CPT-11), 5-fluorouracil (5-FU) and leucovorin (LV) for colorectal liver metastases. BMC Cancer 9: 156, 2009. 
48. Lubezky N, Geva R, Shmueli E, Nakache R, Klausner JM, Figer A and Ben-Haim M: Is there a survival benefit to neoadjuvant versus adjuvant chemotherapy, combined with surgery for resectable colorectal liver metastases? World J Surg 33: 1028-1034, 2009.

49. Ychou M, Hohenberger W, Thezenas S, et al: A randomized phase III study comparing adjuvant 5-fluorouracil/folinic acid with FOLFIRI in patients following complete resection of liver metastases from colorectal cancer. Ann Oncol 20: 1964-1970, 2009.

50. Mitry E, Fields AL, Bleiberg H, et al: Adjuvant chemotherapy after potentially curative resection of metastases from colorectal cancer: a pooled analysis of two randomized trials. J Clin Oncol 26: 4906-4911, 2008.

51. Uzzan B, Mariani P, Nicolas P, Perret, G Morere J and des Guetz G: Systemic or hepatic arterial chemotherapy is useful after curative resection of liver metastases from colorectal cancer. A meta-analysis of randomized controlled trials. J Clin Oncol 26 (Suppl): 4077, 2008.

52. Langer B, Bleiberg H, Labianca R, Shepherd L, et al: Fluorouracil (FU) plus l-leucovorin (1-LV) versus observation after potentially curative resection of liver or lung metastases from colorectal cancer (CRC): results of the ENG (EORTC/NCIC CTG/GIVIO) randomized trial. Proc Am Soc Clin Oncol 21: 592, 2002.

53. Lopez-Ladron A, Salvador J, Bernabe R, et al: Observation versus postoperative chemotherapy after resection of liver metastases in patients with advanced colorectal cancer. Proc Am Soc Clin Oncol 22: 1497, 2003.

54. Portier G, Elias D, Bouche O, et al: Multicenter randomized trial of adjuvant fluorouracil and folinic acid compared with surgery alone after resection of colorectal liver metastases: FFCD ACHBTH AURC 9002 trial. J Clin Oncol 24: 4976-4982, 2006

55. Nordlinger B, Sorbye H, Glimelius B, et al; EORTC Gastro-Intestinal Tract Cancer Group, Cancer Research UK, Arbeitsgruppe Lebermetastasen und-tumoren in der Chirurgischen Arbeitsgemeinschaft Onkologie (ALM-CAO), Australasian Gastro-Intestinal Trials Group (AGITG), Fédération Francophone de Cancérologie Digestive (FFCD): Perioperative chemotherapy with FOLFOX4 and surgery versus surgery alone for resectable liver metastases from colorectal cancer (EORTC Intergroup trial 40983): a randomised controlled trial. Lancet 371: 1007-1016, 2008
56. Buyse M, Burzykowski T, Carroll K, et al: Progression-free survival is a surrogate for survival in advanced colorectal cancer. J Clin Oncol 25: 5218-5224, 2007.

57. Tang PA, Bentzen SM, Chen EX and Siu LL: Surrogate end points for median overall survival in metastatic colorectal cancer: literature-based analysis from 39 randomized controlled trials of first-line chemotherapy. J Clin Oncol 25: 4562-4568, 2007.

58. Sargent DJ, Patiyil S, Yothers G, et al: ACCENT Group: End points for colon cancer adjuvant trials: observations and recommendations based on individual patient data from 20,898 patients enrolled onto 18 randomized trials from the ACCENT Group. J Clin Oncol 25: 4569-4574, 2007.

59. Sargent DJ, Wieand HS, Haller DG, et al: Disease-free survival versus overall survival as a primary end point for adjuvant colon cancer studies: individual patient data from 20,898 patients on 18 randomized trials. J Clin Oncol 23: 8664-8670, 2005.

60. Masi G, Loupakis F, Pollina L, Vasile E, Cupini S, Ricci S, Brunetti IM, Ferraldeschi R, Naso G, Filipponi F, Pietrabissa A, et al: Long-term outcome of initially unresectable metastatic colorectal cancer patients treated with 5-fluorouracil/leucovorin, oxaliplatin, and irinotecan (FOLFOXIRI) followed by radical surgery of metastases. Ann Surg 249: 420-425, 2009.

61. Folprecht G, Grothey A, Alberts S, et al: Neoadjuvant treatment of unresectable colorectal liver metastases: Correlation between tumour response and resection rates. Ann Oncol 16: 1311-1319, 2005.

62. Nordlinger B and Benoist S: Benefits and risks of neoadjuvant therapy for liver metastases. J Clin Oncol 24: 4954-4955, 2006.

63. Benoist S, Brouquet A, Penna C, et al: Complete response of colorectal liver metastases after chemotherapy: does it mean cure? J Clin Oncol 24: 3939-3945, 2006.

64. Kinkel K, Lu Y, Both M, Warren RS and Thoeni RF: Detection of hepatic metastases from cancers of the gastrointestinal tract by using noninvasive imaging methods (US, CT, MR imaging, PET): a meta-analysis. Radiology 224: 748-756, 2002.

65. Nordlinger B, Van Cutsem E, Rougier P, et al: Does chemotherapy prior to liver resection increase the potential for cure in patients with metastatic colorectal cancer? A report from the European Colorectal Metastases Treatment Group. Eur J Cancer 43: 2037-2045, 2007 